\title{
Raza, raciología y racismo en la obra de Marcelo Bórmida
}

RMA

Antropología Social

\begin{abstract}
Resumen
En este artículo analizo el concepto de raza en los casi diez primeros años de la obra de Marcelo Bórmida (19251978). En estos primeros años lo que este autor considera antropología refiere al desarrollo progresivo de las razas humanas. Esto no significa que no analice problemas lingüísticos, culturales o históricos. Lo que ocurre es que todas estas variables están subordinadas al concepto de raza, a la idea de que lo central en la vida humana es la convivencia, la lucha, la victoria, la derrota o la fusión entre éstas. Por ello, sus estudios no son una sociología sino una raciología. Para este análisis, utilizaremos principalmente dos de sus primeras obras: una sobre el poblamiento de la isla de Pascua (Chile) y otra sobre el poblamiento de la Patagonia (Argentina).
\end{abstract}

Palabras clave: Marcelo Bórmida; raza; Patagonia; Isla de Pascua.

Race, raciology and racism in Marcelo Bórmida's works

\begin{abstract}
In this work the concept of race in the first ten years of Marcelo Bórmida's research is analyzed. In this early period, according to Bórmida, anthropology refers to the progressive development of human races. This does not mean that he avoids analyzing linguistic, cultural or historical problems; all these variables are subordinate to the concept of race. His approach is not sociological but raciological. For this analysis, mainly two of Bormida's early works are studied: on the settlement of Easter Island (Chile), and on the peopling of Patagonia (Argentina).
\end{abstract}

Keywords: Marcelo Bormida; race; Patagonia; Easter Island.

En este artículo analizaré el concepto de raza en los primeros trabajos de Marcelo Bórmida (1925-1978), quien fuera tal vez una de las figuras más controvertidas de la antropología argentina. Originario de la ciudad de Roma, estudió ciencias biológicas en la universidad homónima y trabajó con el raciólogo Sergio Sergi hasta 1946, año en que se radicó en Argentina. Continuó sus estudios en la Facultad de Filosofía y Letras de la Universidad de Buenos Aires (FFyL-UBA) donde obtuvo los títulos de profesor de Historia, licenciado en Antropología y Etnología General y doctor en Filosofía y Letras casi simultáneamente. En 1957 obtuvo por concurso la titularidad de la cátedra de Antropología en la FFyL - UBA, en la que fue sucesivamente Director del Instituto de Antropología del Departamento de Ciencias Antropológicas y del Museo Etnográfico. Es en el momento en que obtiene estas titularidades cuando realiza una crítica a algunos aspectos de la Escuela Histórico-Cultural (EHC), de la que él y gran parte de la comunidad antropológica argentina se consideraban miembros. Escuela de origen germánico, deriva de los estudios filológicos del S. XIX y presupone que si un grupo de lenguas que tenían algo en común derivaban de una lengua madre, y por ende permitía construir un tronco lingüístico, de igual forma se podía inducir que un grupo de culturas emparentadas pertenecía a una cultura originaria, y entonces se podía establecer un ciclo cultural (Fígoli, 1990). En el caso argentino, se la asocia con las posturas políticas de extrema derecha y el racismo (Garbulski, 1991-1992:16); pero liberales como Fernando Márquez Miranda también adhirieron a esta escuela (Briones-Guber, 2008), por lo tanto no podemos establecer un paralelo automático entre la EHC y las posiciones de extrema derecha.

Desde su llegada hasta 1956, Bórmida realizó un viaje a la isla de Pascua (Chile) y nueve a la Patagonia. Ninguno fue demasiado prolongado, pero se lo considerará suficiente como para poder desarrollar una serie de tesis sobre el poblamiento de ambas áreas. Saldrán dos obras centrales: un volumen íntegro de la Revista Runa en dónde desarrollaran el problema del poblamiento en Rapa Nui (Silla,2009), y su tesis doctoral sobre los Patagones. Ambos estudios están bajo la supervisión de José Imbelloni, un especialista en razas y poblamiento de América que abogó por establecer una unidad entre raza y cultura (Arenas-Baffi, 1991-92:168); y que a su vez hegemonizó el campo de la antropología en Argentina durante los dos primeros gobiernos del Gral. 
Juan D. Perón (1945-1955). Los trabajos sobre Pascua y Patagonia son de clara y abierta adhesión a la EHC en la línea considerada Antropología, o sea, a la relación entre raza y cultura, y distinguida de la Etnología, que hará hincapié en el concepto mismo de cultura y no de raza (Bórmida,1958-59:267; Banton,1977:45), posición que adoptará unos años después. En éstas dos áreas geográficas desarrollará sus estudios hasta mediados de la década del '50, y su categoría de análisis central será la de raza; no en el sentido del estudio de las relaciones y construcciones sociales marcadas por la racialización que de ciertos fenómenos hacen los grupos humanos, sino en el de que el tipo físico es indicador de conductas morales y culturales. Derivados de raza serán los de pureza y mestizaje. Analizaremos cada uno de ellos así como sus implicancias, pero intentando no hacer ni una apología ni una destrucción a partir de juicios éticos apriorísticos sobre el autor, sino más bien describir ("etnografíar") sus principios teóricos y sus prácticas de investigación, y así también intentar vincular, en alguna medida, las relaciones entre ciencia y política.

\section{Contacto, aculturación e impermeabilidad}

Hay algo que permea toda la obra en torno a los pascuenses: el supuesto de que existiría un corte radical entre la historia de la isla desde que fuera descubierta por los navegantes europeos y la historia anterior a ese contacto. El descubrimiento, desembarco, conquista, rapto de nativos y comercio con los primeros sería diferente del descubrimiento, conquista, guerras y comercio que realizaron los argonautas del Pacífico. Así, las invasiones oceánicas no tendrían la misma penetración que la europea. No sería tan destructora, no quebraría tan radicalmente con la pureza originaria de las poblaciones prehistóricas. Si por un lado Bórmida considera a Europa y parte de Asia como el centro de todo, como el foco de irradiación de todas las culturas y por ende de todas las razas, también hay algo en lo europeo "que mancha". El contacto con occidente hace perder la pureza del bárbaro, para utilizar una terminología que unos años después creará. La historia de la humanidad está así partida en dos grandes períodos, en un antes y un después de la expansión y colonización europea.

Es entonces que se preguntará cómo, una vez realizada las incursiones europeas y continentales a la isla, podemos hacer para encontrar un pascuense puro. Para Bórmida "puro involucra un valor necesariamente relativo y negativo (...) y considerará puros a todos aquellos individuos en los cuales no puede demostrarse la presencia de sangre foránea, es decir, aquellos cuyos antepasados, hasta donde la memoria alcance, pertenecieron a ese grupo humano que llegó en las diferentes migraciones oceánicas anteriores a los europeos (Bórmida 1951:181). Es así que mientras las mezclas que se producen entre no europeos y en el pasado son puras, cuando la mezcla se origina por la expansión europea se denominaran mestizaje, pérdida de pureza racial y decadencia cultural. Incluso la descendencia producto de matrimonios entre pascuenses y tahitianos (ambos polinesios), producto de la incursión europea, es considerada mestiza.

El mismo problema es planteado en Patagonia, porque obviamente la constitución de los Estados nacionales argentino y chileno son considerados sustancialmente diferentes a las poblaciones autóctonas, debido a la "impermeabilidad cultural entre el indígena patagónico y el poblador europeo" (Bórmida 1950:234). Pero también existirá otro intruso, "un elemento racial foráneo de origen andino: el Araucano" (Bórmida 1953-54:19), término acuñado por los españoles para denominar a los mapuches; y de la misma forma que los tahitianos que llegaron con los europeos no serán considerados pobladores autóctonos de Pascua, tampoco serán pobladores autóctonos los araucanos que habitan la Patagonia del actual territorio argentino, debido a que llegaron en tiempo simultáneo al poblamiento europeo.

El concepto de impermeabilidad cultural, también se aprecia en su estudio sobre los pascuenses pues dirá, respecto a los informantes, que

"estos pascuenses tan profundamente aculturados a la civilización europea en la religión, la vivienda y la vestimenta, nos narraron las sangrientas luchas de sus antepasados con la espontaneidad que surge de una noción hondamente arraigada en el espíritu, tan presentes y vivas como si fuesen hechos ocurridos pocos años atrás" (Bórmida 1951:18);

y al referirse a uno de sus informantes dirá que

"el objeto de su vida es efectuar un viaje a Tahití con un bote por él construido. Cuando le preguntamos la finalidad de este viaje no supo definirla bien; hablaba vagamente de una inquietud, de una necesidad de ver cosas nuevas: extraño residuo de aquella antigua sed de espacio, que determinó las estupendas hazañas de los argonautas polinesios" (Bórmida 1951:20).

Bórmida encuentra aquí la persistencia de un stratum: la permanencia, pese al proceso de aculturación y modernización, de ideas, prácticas y valores del pasado (Imbelloni, en Briones y Guber 2008), y es claro que este stratum refuerza la idea de impermeabilidad cultural. Si el mundo del indígena y el mundo del europeo son impermeables, por más que el indígena se aculture adquiriendo el cristianismo, las vestimentas, viviendas europeas, etc., habrá un stratum que lo hace mantenerse bárbaro, que en este caso, sigue rememorando las hazañas de los antiguos navegantes polinesios.

Ahora bien, la búsqueda de esta pureza es descripta como 
una penuria que comienza con su propio viaje hasta esa isla. Relata como en 1950 consiguen viajar con el apoyo del gobierno de Chile y la ayuda financiera de la FFyL UBA. Antes de llegar, ya tenía una lista provisoria de puros basado en censos anteriores a su llegada, como la lista armada por Drapkin. Una vez en la isla, el Dr. Sebastián Englert, de la orden Capuchina y el único misionero que residía en la isla, le ayudó a señalar y elegir "los representantes puros de la población nativa de Pascua" pues decía conocer la genealogía de todas las familias de la isla" (Bórmida 1951:179). La moral sexual pascuense facilitó en parte el descubrimiento de ejemplares puros. Según Bórmida, los hijos no tenían problema en decir que el marido de su madre no era su padre biológico, pues no representaba descalificación social alguna, razón por la cual consideraba que los lazos matrimoniales eran débiles. Al no existir una barrera moral que les impida a los nativos declarar sus actos sexuales, pudo descubrir a los pascuenses puros (Bórmida 1951:183) y descartar los mestizos. Pero hubo otro factor que también lo ayudó: el profundo recuerdo que los pascuenses poseían de "el origen forastero de algún antecesor, a veces tan remoto como para no recordar ni el nombre ni el grado de parentesco" (Bórmida 1951:183). Asumo que este dato le servirá a Bórmida para fundamentar, como veremos más adelante, la validez histórica de los relatos que recopiló sobre las guerras en Pascua, pero además existe un supuesto de que la mezcla (cultural y racial) queda marcada en la memoria. Finalmente, consideró que consiguió una selección de puros aceptable a partir de la lista de Drapkin, que contenía el censo de puros, la revisión de la misma por parte de Englert, los informes del enfermero que realizó gran parte de la revisación sanitaria, y los informes de los propios nativos (Bórmida 1951:183).

Otro problema que debió superar refiere a "la naturaleza inquieta de los pascuenses, quienes no siempre se someten de buena gana a las largas operaciones de medición y no esperan su turno sino se les puede atender en seguida" (Bórmida 1951:183). Esta queja, en dónde pareciera que los nativos deberían estar preocupados por ser medidos y por ende tener la paciencia de esperar su turno, es algo más que comprensible si tomamos en cuenta las extremadamente minuciosas mediciones que atañen a todo el cuerpo. Pese a todo, consiguió medir a "38 individuos masculinos y femeninos, todos pascuenses puros, adultos, sanos y de desarrollo normal" (Bórmida 1951:185). Esto es importante, pues cualquier alteración patológica del grupo produciría una desviación de la muestra, algo que quedará más claro cuando analice las razas patagónicas. Las observaciones, análisis y mediciones comprenden hasta los detalles corporales más ínfimos, y una de las mediciones (la altura de la cabeza) fue realizada con un acrómetro. Concluye su estudio somatológico alegando que existe una prioridad de los caracteres somáticos polinesios (europoides) a los melanesios (negroides).
Respecto al acrómetro, en 1949 Bórmida escribió un artículo señalando las ventajas de este instrumento inventado por Imbelloni para medir la altura cefálica; algo que según el autor no era atendido por una buena parte de los antropólogos de la época, que sólo medían longitud y ancho en sus estudios craneológicos (Bórmida 1951:126). En el mismo artículo se afirma que en las poblaciones europeas la altura cefálica no era importante para distinguir las razas, pero sí lo era en América; e Imbelloni, si bien no fue el primero, sí fue el que desarrolló y demostró la importancia de aplicar esta medida en América (Bórmida 1951:127). El acrómetro tampoco fue el primer instrumento diseñado para medir la altura cefálica, pero Bórmida señala que es más exacto que los otros y más fácil y rápido de utilizar.

Volviendo al problema del poblamiento de Pascua, en otro artículo Bórmida desarrollará el problema de una temática nativa que parece recurrente: la guerra entre los Hanau-eepe y los Hanau-momoko, en principio orejas largas y orejas chicas respectivamente. Recopila de primera mano una buena cantidad de versiones sobre esta "extraña tradición aborigen que narra la antigua lucha de dos grupos étnicos que compartieron un tiempo el dominio de la isla" (Bórmida 1951:5), y también transcribe en su trabajo los diferentes relatos tomados por viajeros y residentes; entre ellos el de Vives Solar, gobernador por cuatro años en la isla que afirma, en un artículo aparecido en la Revista Chilena de Historia y Geografía de 1920, que "antiguamente existían dos razas que se distinguían principalmente entre sí por la extensión de sus orejas". Los orejas largas conocían el arte de las construcciones megalíticas y "probablemente en estas construcciones obligaban a trabajar a los orejas chicas, y así se concibe la tirria con que éstos miraban esas clases de monumentos tan costosos como inútiles" (en Bórmida 1951:11). Finalmente, y en una rebelión, asesinaron a todos los orejas largas y se los comieron en una gran fiesta caníbal. Sólo quedó uno que finalmente se integró casándose con una mujer oreja chica. Este habría sido el fin de los orejas largas y el fin de la época de construcción de grandes monumentos líticos en la isla, y por ende también, el comienzo de su decadencia. Según Bórmida, y en relación a los relatos existentes, es evidente que existió alguna diferencia entre los grupos rivales relativa a la industria megalítica, pues de otra manera no se explicaría que tantas versiones se refieran a ella. Considera que probablemente el arte megalítico fue llevado por los Hanau-momoko, al igual que la deformación de las orejas (Bórmida 1951:28). El canibalismo, por el contrario, debió haber sido llevado por los Hanau-eepe, en una migración posterior (Bórmida 1951:29).

La guerra y las invasiones son una preocupación central para Bórmida, porque pareciera que considera que la humanidad y las razas se regulan a partir de las guerras y el conflicto interracial. Probablemente uno de los que influyó en esta idea haya sido su maestro Imbelloni, 
ya que en artículos muy tempranos, y discutiendo con los intelectuales pacifistas la situación de Europa, y en especial de Italia, en los comienzos de la Primera Guerra Mundial, considerará que "el estado de guerra es complementario al estado de paz" (Imbelloni 1916: 383) y que la primera es un hecho inherente a la vida, a los organismos, a los seres humanos a las naciones y a los Estados. De esta manera:

"(en) cada pueblo debe a priori considerarse legítimo siempre el nacionalismo, y hasta su eventual imperialismo. Un pueblo, nos enseña la historia, que haya conseguido su madurez nacional, o sea un grado bastante firme de su proceso individuativo, puede acaso poseer todavía una tal reserva de fuerza afirmativa que deberá necesariamente proyectarla sobre el mundo exterior. Aquel pueblo tiende, entonces, hacia el imperio; pero, naturalmente, es otro tanto legítima la defensa de los demás contra el imperialismo" (Imbelloni 1916: 386).

Para Imbelloni, así como para muchos pensadores del Siglo XIX y buena parte del XX, las razas, los Estados o las naciones, una vez estabilizadas y desarrolladas, indefectiblemente entraban en conflicto y lucha.

Tal vez por esta razón Bórmida desconfiaba de los relatos que, como los de Vives Solar, afirmaban que el conflicto entre los orejas largas y chicas fue debido a que estos últimos no soportaban la explotación de los primeros, lo que sería una posición que asuma un conflicto de tipo económico, y de clase. Por el contrario, considera que

"el más elemental sentido histórico nos dice que la causa verdadera de la guerra debe haber sido la referida por Knoche (otro de los que toma un relato): aquel afán de dominio que ha venido actuando durante toda la historia de la humanidad entre pueblos colindantes. Los demás motivos consignados en la tradición deben considerarse como ocasionales o, quizás, como simples pretextos" (Bórmida 1951:35).

Existiría entonces un sentimiento innato en la humanidad de ocupar, invadir y hasta exterminar a los pueblos vecinos; y tal vez, en su perspectiva, este sea el verdadero motivo de las migraciones.

Bórmida llega a la conclusión de que no recopiló mitos sino tradiciones históricas, pues las narrativas que obtuvo no contenían elementos de orden fantástico. Estas tradiciones históricas relatarían más o menos objetivamente hechos que se han conservado en la memoria popular tales como ocurrieron. Entonces esos relatos serían una crónica no escrita, pues la objetividad de sus elementos sería patente y en ninguna de las versiones habría hechos o personajes míticos, sumado a que algunos datos se podrían corroborar por testimonios de viajeros europeos. Así, las narraciones que hacen los pascuenses son en última instancia de iguales características y finalidades que los documentos occidentales y, si bien no sería Historia sino tradiciones históricas tendrían, en realidad, la validez de una fuente documental susceptible de ser analizada por la ciencia de la Historia.

Ahora bien, hasta aquí tenemos un estudio sobre narrativas de tipo mitológico, legendario o que hasta podríamos actualizar alegando que corresponden al campo de la historia oral o la memoria, trayendo a Bórmida a nuestros propios parámetros de análisis. Sin embargo, lo que me parece interesante es que si bien utiliza a un especialista en leyendas como Arnold Van Gennep ${ }^{1}$ (1873-1957) y trabaja a partir de crónicas y relatos recopilados por él mismo y por colegas de diferente índole, su conclusión final será que descubrió que la diferencia real entre los dos grupos no es cultural sino morfológica, o sea racial. Afirmará entonces que la distinción entre orejas largas y chicas no tiene que ver con una práctica cultural (la deformación de las orejas) sino con que somatológicamente un grupo tenía las orejas más alargadas que el otro. Además alegará que la casi totalidad de los autores traducen Hanau-eepe como oreja grande y el de Hanau-momoko como oreja corta, y que consideran que esta diferencia de tamaño de las orejas fuese producida por una distensión artificial del lóbulo practicada originalmente por los Hanau eepe y no por el grupo rival. Dirá que Hanau significa gente, pero que el término eepe no significa oreja, ni nada que envuelva el sentido de oreja larga; es simplemente un adjetivo que se traduce como ancho, corpulento, macizo. Señala que según Englert, quien había escrito un diccionario pascuense, eepe ha sufrido una falsa interpretación debido a su semejanza fonética con epe, oreja; en consecuencia la traducción de Hanau-eepe como orejas largas es completamente falsa, siendo la correcta gente corpulenta, la que se completa a veces con el agregado de tahata hanau-eepe, que traduce como hombres de raza corpulenta. A su vez, momoko no es sino la duplicación de moko, lagartija, y significa puntiagudo, delgado. Según Bórmida, el descubrimiento de la diferencia racial, expresada por los nombres de los grupos rivales, es de gran importancia para el problema de la doble migración de Pascua, pues excluye la posibilidad de que se tratara de simples agregados de tribus o clanes, como sería dado pensar si lo único que los diferenciara fuera una costumbre deformatoria y fuera ésta la sola diferencia transmitida por la tradición (Bórmida 1951:27). Afirmará que los relatos confirman que las deformaciones continuaron practicándose aún después de la destrucción de los Hanau-eepe, que como vimos fueron asesinados

\footnotetext{
${ }^{1}$ Van Gennep es muy respetado por Bórmida y debemos recodar que, si bien el primero pertenece a la tradición francesa, fue un crítico del contenido del Année sociologique y sus métodos (Zumwalt en Needham, 2006:6).
} 
y comidos por los Hanau-momoko durante la guerra. Pero la afirmación objetiva de que existieron dos razas radica en que en su análisis somatológico encontró que "el lóbulo pequeño y a menudo pegado es característica casi general entre los pascuenses puros de ambos sexos" (Bórmida 1951:25). Todos los habitantes puros actuales tienen orejas cortas. Simultáneamente se consideran descendientes de los Hanau-momoko, ya que ninguno o pocos quedaron del otro grupo. Así el análisis somatológico y racial nos da indicadores irrefutables sobre ciertos procesos históricos y sociales que ocurrieron en la isla. Por ende, el aspecto cultural está subordinado al aspecto racial. Su análisis no es sociológico o cultural, sino raciológico, porque aún la lingüística le servirá para apoyar su tesis de que encontró dos razas, dos términos nativos que refieren a sus rasgos morfológicos y que los pascuenses utilizaban para autoadcribirse. Según Bórmida, los Hanau-eepe llevaron a la isla la práctica del canibalismo y la deformación de las orejas, que no influyó en la denominación de estos. Posteriormente los Hanaumomoko fueron aculturados en estas prácticas. La guerra étnica fue en verdad, y en su interpretación, una guerra de control del territorio, pero no por intereses económicos, políticos o culturales. La guerra entre ambos grupos se debió por una necesidad casi innata de que una raza debe avanzar sobre otra, y eliminarla o asimilarla. Vemos también que si bien la aculturación es posible, finalmente cada raza tiene una cultura, un saber y determinadas costumbres, y esto es lo central en su análisis. Son así las razas las que portan cultura, que se destruyen, mezclan o imponen sus condiciones de existencia a otras razas, a partir de las migraciones, las invasiones y la guerra. Este presupuesto hace que se genere la necesidad de analizar las relaciones entre raza y cultura (y en rigor también lengua), tarea a lo cual el autor está abocado.

\section{Concluye entonces que}

"Ios Hanau-momoko formaron parte de aquella antigua corriente proto-polinesia que, intensamente aculturada a las civilizaciones de Asia e Insulindia, llevó consigo la industria megalítica y, quizás, la cultura de los ariki; sus rastros señalados por las construcciones megalíticas pueden seguirse a través de un inmenso arco que va desde Insulindia, a través de Tinian, Ponape, Kusaie, Tonga tapu, Samoa, Rarotonga, Tahití, las Marquesas, las Islas Australes y Pitcairn hasta la Isla de Pascua. La segunda oleada migratoria, los Hanau-eepe, fue debida a una diáspora más moderna siempre derivada de la anterior, que, ya empobrecida culturalmente y contaminada por elementos no-polinesios tales como el canibalismo, pobló entre otros lugares Nueva Zelandia. No deja de ser sugestivo el hecho que, como Pascua, también Nueva Zelandia conserva el recuerdo de dos poblamientos sucesivos, los Moriori y los Maorí, debiéndose posiblemente a los primeros los elementos megalíticos que existen en aquella isla y a los segundos la introducción del canibalismo; la única diferencia es que mientras en Nueva Zelandia los invasores Maorí exterminaron a los antiguos habitantes, en Pascua ocurrió lo contrario y la cultura más antigua continuó desarrollándose hasta su contacto con los europeos" (Bórmida 1951:62).

Queda claro en su perspectiva el foco original de irradiación es Asia, que a Pascua llegaron al menos dos oleadas migratorias y que estas oleadas correspondían a dos razas diferentes en lo somático y cultural. Hay también una teoría implícita de la degeneración y la decadencia, ya que la última oleada está empobrecida culturalmente debido a la mezcla de elementos melanesios. Establece entonces una clara jerarquía entre los Hanau-momoko, conocedora del arte megalítico, las deformaciones de las orejas y más cercana a la irradiación original asiática y los Hanau-eepe, culturalmente empobrecidos y aculturados por elementos melanesios como el canibalismo.

\section{Los cráneos, indicadores de las razas}

Dirigido y abalado por Imbelloni, en 1953 Bórmida defenderá su tesis doctoral en la FFyL-UBA titulada LoS antiguos patagones; y será publicada en forma integral en el volumen VI de la revista Runa de 1953-54. También un resumen será presentado bajo el título "Recientes estudios sobre los antiguos habitantes de la Patagonia", en el Congreso Internacional de Americanistas de 1954 realizado en São Paulo, cuyo presidente en esa oportunidad fuera Paul Rivet, quien defendía las dos posiciones respecto al poblamiento de América, la del estrecho de Bering por el norte y la de Oceanía por América del Sur (Rivet [1957]1974). En 1949 Bórmida ya había publicado "Sepultura colectiva bajo roca en la Patagonia Austral", artículo resultado de la "Expedición antropológica a Santa Cruz de la Comisión del Museo Etnográfico" dirigida por Imbelloni. Si bien la expedición está dedicada al estudio del indio viviente (Bórmida 1949:148), el artículo en cuestión analiza el hallazgo de una sepultura colectiva. Pero cómo todos los cráneos están destruidos, considerará que los huesos encontrados son "de escasa importancia para un diagnóstico racial" (Bórmida 1949:154). La sistematización de la información disponible para Patagonia realizada por Bórmida es considerada una obra clave de la escuela morfológica argentina (Carnese et al. 1991-1992:40).

En el caso de los patagones, Bórmida volverá a realizar el modus operandi marcado por la EHC, pero en este caso su posición raciológica será mas acentuada que en el estudio de los pascuenses, pues señalará que

"el objetivo último de una moderna craneología debe ser la reconstrucción de la historia racial de un área humana, lo que se resuelve, en la práctica, en 
la identificación de los distintos grupos raciales que la han poblado - su hábitat, su cronología relativa y su biodinámica recíproca. Esta es la finalidad que nos proponemos en el presente trabajo" (Bórmida 1953-1954:18)

Identificar los distintos grupos raciales para luego realizar una cronología de la incursión de las diferentes razas al territorio, así como ponerlas en relación unas con otras y no verlas en forma aislada serán los objetivos centrales de su estudio. Para ello comienza aclarando la relación que existe entre craneología y raciología, dejando claro que la primera está subordinada a la segunda:

"La craneología no es más que un instrumento, entre los más útiles en verdad, de la raciología; su misión es la de reconstruir los panoramas raciales antiguos de áreas humanas cada vez más amplias y su historia, intentado llevarlas a una profundidad siempre mayor. Esa doble dimensión, espacial y temporal, que brota de la naturaleza imperecedera del material que estudia, es justamente la que da a la craneología su razón de ser y la hace insustituible dentro de las ciencias del hombre. Tal visión histórica de la craneología de Patagonia es la que ha informado nuestro trabajo" (Bórmida 1953-1954:26).

Tenemos en esta posición algo semejante a la relación que uno de los grandes sistematizadores de la EHC como Fritz Graebner señalara entre el artefacto lítico y la narrativa. Así como el producto objetivo e inmutable del pasado es el objeto lítico y no los productos de las sociedades no occidentales de la actualidad, el cráneo rescatado de un yacimiento tendrá las mismas características: es el registro objetivo e indiscutible del pasado. Esto permite reconstruir la movilidad de las razas humanas de la antigüedad.

Buscando individualizar formas craneanas que tengan valor racial, hará hincapié en la relación cráneo-cara, y ante todo cual de estos cráneos y caras son los que portaron los primeros habitantes, los originales. Alegará que si en los cráneos de Patagonia existe una forma facial común a varias formas neurocraneanas es evidente que no son sino unidades sistemáticas menores agrupadas alrededor de otra más comprensiva, que se caracteriza justamente por esa forma facial común. Lo esencial del problema es entonces investigar cuál es esta unidad más comprensiva, es decir, cuál es la forma craneana que estuvo asociada en origen a la cara en cuestión. Esto es lo que considera que es el método craneológico (Bórmida 1953-1954:23). Entonces, sobre la base de las asociaciones cráneo-cara intentará descubrir si se tratan de tipos primarios o secundarios, es decir, si son razas o simples variedades de una misma raza (:27). Aquí raza va asociado a tipo, o sea a la existencia de una forma absoluta por detrás de cualquier diversidad aparente que pueda mostrar cada cráneo o cráneo-cara en particular.
Respecto al concepto de tipo, al analizar la idea de raza imperante en muchos de los científicos europeos del Siglo XIX, Michael Banton opina que es útil abordarla desde esta categoría que desarrolló primeramente Georges Cuvier (1769-1832). El tipo no estaba ligado a cualquier nivel clasificatorio de la zoología y esto permitía referirse más fácilmente a los tipos físicos característicos de determinadas naciones. Se podía entonces decir que un cráneo se aproximaba al tipo negro sin necesariamente tener que establecer exactamente en qué consistía ese tipo (Banton 1977:40). La noción de tipo también implicaba que había o hay una forma física pura por detrás de la aparente diversidad. En el caso de Imbelloni, como vimos uno de los maestros de Bórmida, Arenas y Baffi también consideran que su noción de tipo resulta de una idealización del conjunto que representa, y no es necesario que tenga una existencia real, no resulta de un promedio estadístico, y no es ni siquiera una moda, sino que apunta a revelar la esencia de su clase y reúne todos los atributos de ella sin que existan obligatoriamente en conjunto en un individuo (Arenas y Baffi 1991-1992:171).

Ahora bien, ¿cómo sabemos que estamos trabajando con muestras craneales auténticas? Como en Pascua, Bórmida primero analizará los trabajos previos de craneología patagónica. Dirá que Sergi, con quien estudió en Roma, se dedicó desde 1928 a 1930 intensamente al estudio de los cráneos patagónicos (Bórmida 1953-1954:15). Es interesante señalar que todo el trabajo discute con autores anteriores a 1930. No queda claro si la razón es que la Segunda Guerra Mundial no permitió que los estudiosos europeos se ocuparan de estos problemas o que este problema ya fuera obsoleto para la ciencia europea. Lo que sí es evidente es que decide discutir con autores anteriores a esta fecha, y que poseían una visión raciológica del problema. Señala que es notable cómo en los últimos decenios la producción craneológica acerca de Patagonia ha ido disminuyendo, a pesar de que el material es hoy más abundante. Bórmida atribuye esta pérdida de vitalidad de un problema en otros tiempos tan actual e interesante, no puede dejar de atribuirse en gran parte a lo escaso y confuso de los resultados (Bórmida 1953-1954:26). En su opinión, la craneología patagónica no se ha desarrollado de forma fructífera. Una de las razones es que los estudiosos no han contado ni con la calidad ni con la cantidad suficiente de material, ya que hasta antes de la ocupación militar argentina, en 1880, era difícil recorrer la región para los occidentales.

En su caso particular, alegará que tiene una buena muestra: 350 piezas inéditas procedentes de Patagonia, 11 Onas, y una serie de araucanos de Neuquén y varios fueguinos, estos dos últimos con fines comparativos. Afirma que es la serie más numerosa de los estudiados, la más completa en cuanto a extensión geográfica y el mejor documentado en cuanto a su procedencia y condiciones de hallazgo (Bórmida 1953-1954:27), ya que en su opinión los trabajos anteriores mostraron en general un "descuido 
en la separación de los diferentes yacimientos de una misma región" (Bórmida 1953-1954:28). También alegará que los antropólogos europeos no están habituados a detectar la deformación intencional craneana, típica de muchos pueblos americanos. Esta falta de cuidado hará que muchos de sus resultados hayan sido incorrectos, pues sus muestras estarían viciadas. Remarcará que Imbelloni ya había descubierto este aspecto en 1923, demostrando que la morfología del frontal no es natural sino debida a una deformación cefálica intencional, contradiciendo con ello la afirmación expuesta en lo que Bórmida considera uno de los estudios más citados y conocidos, Les anciens patagons, de René Verneau, editado en 1903 y que afirmaba que "en (el entonces Territorio Nacional de) Santa Cruz no hay deformados" (Bórmida 1953-1954:15).

Aclarará que en su caso, el 65,3\% de los cráneos de su muestra están deformados intencionalmente con distintas intensidades y modalidades (Bórmida 1953-1954:42), por ende, y en principio, son inutilizables. Ahora bien, una vez más irá de la cultura a la raza priorizando esta última en su análisis, pues alegará que la deformación puede utilizarse como guía para separar cronológicamente los yacimientos y determinar distintos momentos de la historia étnica:

"es evidente que las diferentes plásticas craneanas que hemos descripto, aún perteneciendo todas al modelo Tabular Erecto, son el resultado de la aplicación de otros tantos métodos e instrumentos, siempre, se entiende, dentro de los aparatos del tipo 'cuna'; estas diferencias instrumentales revelan distintas influencias culturales procedentes de la región andina, que debe considerarse foco principal de las deformaciones craneanas en Sudamérica. Como hipótesis de trabajo podemos suponer que dichas influencias han obrado en grupos humanos que en su origen no eran deformadores, y en momentos cronológicos sucesivos; siendo así, si colocamos en un mapa todos nuestros yacimientos y eliminamos luego todos los que contengan cráneos deformados, tendremos con los restantes un panorama aproximado de la craneología de Patagonia antes que comenzasen a actuar en ellas las influencias culturales, y eventualmente raciales, de los pueblos deformadores de los Andes (...) Si admitimos que los distintos tipos de deformación planofrontal, planolámbdico y pseudocircular representan distintas influencias culturales andinas, posteriores al momento predeformatorio de Patagonia, puede postularse razonablemente que también corresponden a momentos sucesivos de la historia étnica de esta región. En consecuencia, el estudio en conjunto de los yacimientos que presentan uno de los tipos de deformación nos permitirá hacernos una idea del estado racial de Patagonia en un determinado momento de su historia" (Bórmida 1953-1954:48)
Vemos en este párrafo varios de sus presupuestos de investigación. Las deformaciones son intencionales, pero esta intencionalidad no representa simplemente una cultura o una sociedad, sino un tipo racial. Por ende la cultura, en este caso las técnicas de deformación de la cabeza, está asociada a la raza. También vemos que hubo en Patagonia un punto cero, originario y puro, en dónde la deformación intencional no era conocida. Esta sería la cultura-raza originaria. ¿Cómo podemos saber que este grupo existió alguna vez? Primero porque dice encontrar una leve disminución de los cráneos deformados de norte a sur. Así induce que las deformaciones vinieron del norte y los no deformados quedaron arrinconados en el sur (Bórmida 1953-1954:50). Pero también porque "bajo el punto de vista culturológico, una deformación cefálica en un pueblo de cazadores, como los Patagones, es un absurdo" (Bórmida 1953-1954:49). Lo interesante es que reconoce la invención de una práctica como la deformatoria fuera de Eurasia, y le atribuye a las culturas andinas de América el mérito de haber realizado esta creación, susceptible de ser difundida. Esto es lo que diferencia la EHC de otras ramas difusionistas, que eran más radicales en el reconocimiento de focos de invención e irradiación. Pero por otro lado, en el párrafo se asume que hay altas, y por ende bajas culturas, que ciertas prácticas sólo pueden ser inventadas por las primeras y que las segundas a lo sumo pueden copiarlas o imitarlas a partir de un centro de creación. Más allá del establecimiento de una nueva jerarquía cultural (y por ende racial), es evidente que existe en Bórmida una serie de elementos apriorísticos que influyen de manera decisiva en sus conclusiones.

Estas especulaciones y apriorismos eran defendidas como algo positivo en la EHC, y por ejemplo otro miembro también recientemente llegado al país como Oswald Menghín alegaba que

\begin{abstract}
"las lagunas de nuestro saber al respecto son enormes, y no hay posibilidad de franquearlas sino mediante hipótesis más o menos fundadas; es inevitable que en ellas las opiniones subjetivas desempeñen un papel importante. Eso no puede censurarse, pues cuando el material empírico y la observación directa terminan, ocupan su puesto la combinación y la deducción, y cada idea metódicamente desarrollada tiene el mismo derecho científico que las demás" (Bórmida 19531954:201).
\end{abstract}

Esta escuela, y Bórmida en particular, estaba muy preocupado en objetivar el dato. En mostrar la calidad y cantidad de sus muestras, en explicitar todos sus presupuestos y el camino recorrido de la investigación para finalmente desarrollar y defender sus conclusiones. Esto lo convierte en un verdadero científico, y por ello no podemos rotular su racismo como mera ideología que sólo tiene pretensiones políticas. Hay una pretensión de 
verdad en sus postulados, y creo que la importancia de estudiar estos antropólogos radica justamente en que eran científicos, no ideólogos o ensayistas políticos. Pero por ahora quisiera sólo centrarme en el hecho de que en base a descubrimientos objetivos y objetivados, más algunas especulaciones y postulados apriorísticos, deducirá que cada forma es una oleada en un área cuyo origen no tenía la práctica de la deformación. Lo curioso es que esto no permite descubrir la difusión cultural de una práctica particular de deformación, sino la difusión de las diferentes razas que, portando cada una de ellas diferentes prácticas deformatorias, habrían incursionado en la Patagonia. Cada técnica de deformación craneana no revela tanto una cultura o sociedad diferente, sino una raza diferente que porta determinados rasgos culturales y morales. Así, las deformaciones craneanas, en principio una práctica cultural como el canibalismo o las deformaciones de la orejas de los pascuenses, terminan siendo indicadores de diferencias raciales, y de diferentes invasiones realizadas desde las áreas mas desarrolladas, las altas culturas andinas, hacia los confines australes. Los grupos relictarios quedarían arrinconados en Tierra del Fuego. Por ende también serían los más antiguos; y de una importancia fundamental, pues de acuerdo a la concepción de la EHC serían portadores de algunos rasgos de la cultura original o primera, y en opinión de por ejemplo Menghín, "en ningún continente existen residuos de la relativa cultura primordial en mayor número que en América" (Bórmida 1953-1954:203). Desde esta perspectiva, no hay creatividad en Patagonia, sólo asimila o resiste invasiones y prestaciones desde centros más desarrollados y con más inventiva. América tiene la respuesta del origen europeo, pero no hay nada o poco de nuevo en América, sólo residuos de la pureza original euroasiática. De ahí que el pensamiento de Bórmida sea profundamente eurocéntrico, pero realizado desde América.

Un punto que es necesario desarrollar es el hecho de que pese a que Bórmida cree en una unidad entre raza y cultura, no significa que necesariamente sean indisociables. En su opinión, y en concordancia con los saberes de esa época, una raza se puede descubrir a partir del estudio de los diferentes cráneos de una población, pues considera que se pueden encontrar grupos homogéneos de cráneos con poca variabilidad:

"Toda forma craneana tiene dentro de su propia morfología una variabilidad que es solamente cuantitativa, pero que nunca llega a hacerse cualitativa; ninguna variación de las dimensiones absolutas ni de posición entre las mismas podría trasformar la forma de nuestro cráneo $a$ en la del cráneo $b$; ninguno de los elementos que integran cada una de estas formas (morfología de la bóveda craneana, inclinación de las paredes laterales, etc.) tiene en sí las posibilidades de variación que permite relacionarlo, por transiciones, con el elemento análogo de la otra. Esta visión intuitiva se halla confirmada por el hecho de no existir en la realidad formas de transición; los cráneos en cuestión integran grupos morfológicos cuyas variaciones extremas nunca se superponen y cuyos componentes se asemejan entre sí más de los que se asemejan entre los demás" (Bórmida 1953-1954:61).

Al menos para el caso patagónico, dirá que no encuentra un continuum entre su muestra craneal sino ciertas series que son discretas, y por ello no son diferentes variedades de una misma raza, sino razas diferentes. Encontramos así grupos puros, homogéneos que pueden aglutinarse en una taxonomía y colocarlos como una raza, o mejor como un tipo racial. Entonces ¿es imposible que estos grupos se hayan mezclado entre sí? No necesariamente. La mezcla es posible, pero sólo tiene importancia cuando generan otro nuevo grupo armónico, formando una nueva raza:

"en el mestizaje entre razas puras, los caracteres
que son típicos de cada una de ellas no se
mezclan caprichosamente, sino que, después de
un cierto número de generaciones, durante las
cuales el juego genético de esos caracteres busca
un equilibrio estable, vuelven a cristalizar en un
conjunto armónico y constante. Se produce de
esta manera una nueva unidad taxonómica que
participa de los caracteres de las dos unidades
madres y que es genéticamente estable, y se
originan así esas razas metamórficas que tan
importante papel han desempeñado en la historia
racial de la humanidad" (Bórmida 1953-1954:82).

Bórmida encontrará en estas muestras "unidades sistemáticas de diferente rango" (Bórmida 1953-1954: 83), lo que le permitirá discriminar diferentes tipos de razas. Pero también encontrará "afinidades tan estrictas que tan sólo pueden explicarse admitiendo una forma originaria común" (Bórmida 1953-1954: 83). Finalmente encuentra tres razas: la Pámpida, la Láguida y la Fuéguida.

La Patagonia predeformatoria habría estado habitada entonces por una masa pámpida pura que ocupaba toda su región central y septentrional, con excepción del bajo curso del Río Negro. Sufrió en el extremo sud de la Patagonia y en Tierra del Fuego un intenso proceso de metamorfismo racial, debido a la presión genética de los fuéguidos, que la circundaban. A lo largo de la costa atlántica existió una cadena de núcleos fuéguidos, algo discontinua, desde el extremo Sud hasta el Río Negro, y débiles influencias de los fuéguidos de la costa aparecen también en el interior ${ }^{2}$. En la región de la desembocadura

\footnotetext{
${ }^{2}$ En otro artículo referirá al descubrimiento de arpones de hueso fuera del área fueguina, y los considerará de gran interés pues se relaciona de manera directa con la antigua dispersión continental y la influencias de las primitivas culturas de cazadores y recolectores canoeros, representados, en épocas precolombinas, por los nómades acuáticos de la Fueguía (Bórmida 1956:242). Por ello este descubrimiento refuerza sus
} 
del río Negro se hallaba un núcleo Láguido, punta extrema hacia el sud de un área racial muy amplia que se extendía en regiones más septentrionales (Bórmida 1953-1954:90). Los pámpidos finalmente absorbieron a los Láguidos, y aquí comienza un segundo momento, en dónde se encuentra "un tipo racial pámpido inalterado, junto con la deformación planofrontal. Las mismas influencias culturales se extendieron a los núcleos fueguinos de la costa que las recibieron sin modificar sus características raciales originarias" (Bórmida 19531954:91). Por ello concluye que esta última deformación fue introducida sólo en el plano de lo cultural, sin que existiera una migración importante de población. En este caso la cultura tiene independencia de la raza. Esto es un aspecto importante en el pensamiento de la EHC, ya que es una forma de determinar si existió migración o sólo intercambio. Ya Graebener señalaba que si encontramos una práctica cultural sin el correspondiente grupo racial que la originó, es probable que lo que haya existido es intercambio o comercio, pero no migración. Ahora si la práctica o la industria encontrada aparece junto al pueblo que la inventó, entonces será un indicador de que hubo un flujo migratorio, que por invasión, guerra o simple ocupación, llegó al territorio.

Si el segundo momento se debió a una aculturación, en el tercer momento histórico encontrará que

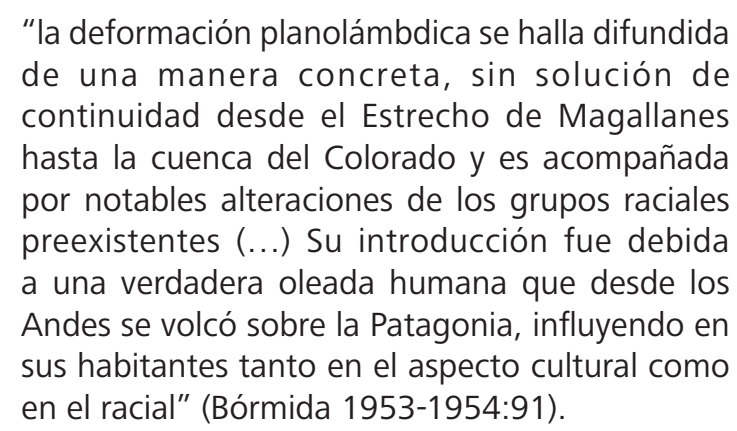

Ante la falta de datos, Bórmida una vez más recurre a la especulación, pues señala que

"El tipo físico antiguo de estos cazadores, tanto en Patagonia como en toda Sudamérica, no nos ha sido revelado por ningún resto osteológico, pero la uniformidad racial de todos sus sobrevivientes hace seguro que pertenecieron a la raza pámpida" (Bórmida 1953-1954:93);

y también establecerá una nueva jerarquía, ya que

"dentro del inevitable choque entre las dos culturas y las dos razas, los fuéguidos debieron desempeñar un papel pasivo; fueron asimilados por los pámpidos o arrinconados definitivamente sobre la costa atlántica y en el extremo más meridional

\footnotetext{
"inducciones craneológicas sobre una amplia dispersión patagónica de núcleos fuegoides" (Bórmida 1956:244).
}

\section{del continente" (Bórmida 1953-1954:96)}

Así determina, además de un choque entre culturas y razas que, como en el caso de los Hanau-momoko y los Hanau-eepe, resultaba inevitable, la existencia de una raza pasiva, susceptible de ser asimilada; por ende también podemos suponer que la raza pámpida era activa. Sabido es que la característica principal de las teorías racistas es establecer jerarquías raciales que se corresponden con jerarquías culturales y sociales. En nuestro caso, si Bórmida establece unidades culturalesraciales más activas que otras, unidades culturales raciales que fueron motores del cambio en la prehistoria, distinguida de otros contingentes que no actuaron debido a su atavismo biológico, el racismo que se desprende de esta postura es evidente ya que establece jerarquías de civilización fundadas en el concepto de raza.

Si bien Bórmida señala sólo tres momentos de la Historia racial de la Patagonia, en realidad podríamos analizar, desde sus propios datos, hasta un cuarto o un quinto momento, pues

\begin{abstract}
“la expansión de los Araucanos de la Patagonia y de la Pampa no había terminado aún a fines del siglo pasado (Siglo XIX); sus influencias habrían continuado hasta nivelar cultural y racialmente a los cazadores del Sur, si el hachazo de la Conquista del Desierto no hubiese cortado al mismo tiempo a los vencedores y a los vencidos" (Bórmida 1953-1954:96).
\end{abstract}

La cuarta invasión la hará otra raza, que por su poder de infiltración también podemos considerar activa, desde los Andes: la Araucana. Pero este proceso no pudo desarrollarse, porque al igual que el descubrimiento de la isla de Pascua por los europeos, que terminó con el desarrollo propio de los pueblos prehistóricos, la Conquista del Desierto iniciada por el gobierno argentino entre 1879 y 1885 terminará también con la dinámica de estas "razas" prehistóricas. Volvemos entonces al problema de la impermeabilidad cultural, ya que la invasión militar argentina parece ser de una naturaleza radicalmente diferente a las invasiones andinas anteriores.

\section{Raza, clase y nación}

En estos raciocinios en dónde la materia y el espíritu se confunden tal vez llame la atención como al leer estos autores que escribieron hacia la mitad del Siglo XX nos quedamos con la sensación de que estamos trabajando con investigadores de un siglo antes, en dónde el debate consistía en si lo que organizaba a los seres humanos era el conflicto de razas, el conflicto de clase o el conflicto entre las naciones. Por ejemplo, tanto Karl Gustav Klemm (1802-1867) como Joseph Arthur de Gobineau (18161882) estaban de acuerdo en que:

a) todas las culturas de importancia tienen en su base 
simbiosis de razas;

b) existen diferentes tipos humanos, que Gobineau denominó fuertes y débiles y Klemm activos y pasivos; c) las razas migran, o al menos migran las activas; d) la migración lleva a la conquista de los fuertes sobre lo débiles;

e) como resultado de la conquista, las razas entran en una simbiosis que, por miscigenación o exterminio, acaba con la disolución de la raza activa conquistadora como una unidad diferente;

f) cuando se disuelve la raza activa, desaparece la tensión política y se establece una sociedad igualitaria (Banton 1977: 52).

Bórmida no cita a estos autores, pero de lo que analizamos creo se desprenden muchas similitudes, por lo que hace pensar que debió existir algún tipo de influencia directa o indirecta de este tipo de pensamiento. Planteos que formulan la pregunta de si lo central en el ser humano, como ser que habita en asociación con otras personas y otros grupos, era su constitución biológica (para lo cual la sociología era casi un sinónimo de la zoología) o existían otras características de los seres humanos de cierta relativa independencia con su carácter físico y composición genética (con lo cual lo zoológico que hay en el ser humano se diferenciaría de su aspecto social o cultural). Tal vez parte de esta sensación se deba a que el conocimiento biológico del Hombre permaneció congelado hasta 1930. En esta década autores como Huxley y Haddon se refirieron a la necesidad de eliminar el concepto de raza aplicado a los seres humanos. Pero en una etapa anterior al descubrimiento del ADN les era difícil demostrar empíricamente que la llave del entendimiento de la poblaciones biológicas, y su relativa rápida evolución, era genética y no morfológica ${ }^{3}$ (Billinger 2007:14). La posterior incorporación de la genética serológica, constituyó un cambio importante desde el punto de vista metodológico, pero no modificó la concepción básica de la variabilidad biológica de la época; y por ello se produjeron cambios en las técnicas más que en los aspectos teóricos y metodológicos, o en la posición del antropólogo con el objeto de estudio. Es entonces recién en la década de 1970 que se abandona el concepto de raza y se propone el estudio de grupos poblacionales $^{4}$ (Carnese et al. 1991-1992: 49).

\footnotetext{
3 También debemos tener en cuenta que hacia la década de 1920, raza se convirtió en un concepto central de la antropología de lengua germana, y la misma disciplina se la denominó Rassenkunde (ciencia racial), simultáneo al avance de los idearios nacionalistas y racistas de la política germánica. Finalizada la Segunda Guerra Mundial, la antropología alemana no sufrió demasiados cambios, continuando con muchos de sus principios fundantes, así como muchos de los investigadores que habían trabajado durante la era Nazi (Kaszycka et al. 2009:51). No queremos hacer extrapolaciones directas entre la antropología alemana y la que desarrollaba Bórmida, que por otro lado era italiano, no alemán. Pero si creemos que indiscutiblemente estaba influenciado por estos desarrollos teóricos y políticos.

4 Este abandono es relativo, ya que en rigor el concepto de raza como entidad biológica de importancia para el entendimiento humano no ha desaparecido completamente de la investigación científica. Michael
}

De todas maneras, no pasaran muchos años para que la antropología argentina deje esta posición raciológica, que si tiene algo en común con las teorías actuales tal vez debamos buscarlas en la sociobiología y no en la antropología física o biológica, ya que estas últimas en la actualidad no buscan correlaciones entre rasgos biológicos y conducta. Es así que pasarán sólo unos pocos años, y antes de la década del '70, para que un antropólogo en Argentina alegue que

\begin{abstract}
"este enfoque ingenuo del problema del pensamiento humano, asimilado sin más a una función fisiológica cualquiera, tuvo una consecuencia de importancia en la praxis de la investigación; a él se debe el hipertrófico desarrollo de la craneología en la antropología del siglo pasado (Siglo XIX); la masa de las investigaciones que concentró el estudio del cráneo bien justifica la opinión vulgar que confundía la antropología con craneología. Y cuando vemos hoy los centenares de complicados aparatos craneométricos que yacen olvidados en los armarios de los laboratorios, no podemos menos que mirar con indulgencia a aquellos irrespetuosos caricaturistas que representaban burlescamente al antropólogo rodeado de calaveras, y justificar la frase de un mordaz polemista italiano: 'los antropólogos hacen como el coleccionista de armas que estudia una espada a través de la vaina".
\end{abstract}

Por cuestiones de desarrollo de la teoría social y biológica, pero tal vez también por cuestiones de política internacional, así como por hechos más personales como la jubilación y paso a retiro de muchos de los antropólogos de vieja escuela como Imbelloni, era necesario pasar a un tipo de antropología que no tuviera, por lo menos de forma explícita, esas correlaciones entre raza, costumbre y moral, posición que finalmente promulgaba el racismo y había sido al menos una de las causas de la Segunda Guerra Mundial con la consiguientes políticas de limpieza étnica y xenofobia tribal, nada menos que en la propia Europa, el supuesto centro de la civilización y el humanismo.

Si bien excede los límites de este trabajo, lo interesante del caso argentino es que este cambio no terminará con la EHC, sino que hará que muchos investigadores pasen de la antigua antropología a lo que ellos denominaban

\footnotetext{
S. Billinger cita por ejemplo un estudio reciente realizado por Kicher que defiende la tesis de que las razas son socialmente construidas pero también biológicamente reales (Billinger 2007:26). Por otro lado, encuestas realizadas a antropólogos de diferentes países muestran que por ejemplo en los Estados Unidos el concepto de raza es rechazado por más de un $70 \%$ de los entrevistados, pero en Polonia, sólo en $25 \%$ de los antropólogos físicos rechazan el concepto; y en una encuesta realizada entre miembros de la Asociación Europea de Antropólogos, de 125 encuestados el 50\% respondió que las razas existen, y de los que lo afirmaron, el 62\% afirmaba la existencia de diferentes razas humanas distribuidas como subespecies (Kaszycka et al. 2009:45).
} 
etnología, como al principio de este trabajo expliqué. El otro aspecto interesante es que una crítica tan fuerte a la raciología como la que transcribí arriba, en dónde se niega de poder acceder a los valores morales y conductuales a partir de la anatomía y la fisiología, y por ende a lo inútil de realizar estudios craneológicos y de fabricar instrumentos para tal fin, como el Arqueómetro inventado por Imbelloni, haya sido de la autoría del propio Bórmida pocos años después de que realizara sus estudios raciológicos, hacia fines de la década del '50, en un artículo en dónde critica lo que denomina "la antropología del materialismo", o sea, el suponer que se puede acceder a la cultura a partir del conocimiento de la anatomía y la fisiología humana (Bórmida, 1958-59).

Tendrán que pasar todavía varias décadas, hasta los años '80, para que la antropología argentina, como dice Patricia Arenas,

"pase de la antropología del pasado a la antropología del presente configurándose un nuevo campo del saber (y en dónde las minorías) son objeto de la antropología social, que con un alto compromiso humanista e intelectual, estudia los controles de mano de obra, los procesos de estructuración del proletariado rural, la subordinación al capital y reproducción social, la diferenciación social y el conflicto y la expansión de la frontera agrícola" (Arenas 2002-2003:131)

Sin embargo, tal vez debamos reflexionar si la antropología argentina, al cambiar el concepto de raza por el de etnia (alegando de una forma igualmente biologicista que no hay fundamentos biológicos para determinar la existencia de las razas humanas) no impidió el paso de estudiar las relaciones entre las razas hacia una forma mas sociológica del estudio de las relaciones raciales, vista como racialización que los diferentes grupos humanos hacen unos de otros, y que implican formas de jerarquización, dominación y subordinación. En la actualidad, creo son muchos los antropólogos argentinos que opinan que no es necesario estudiar los conceptos y motivaciones generados por la creencia (y certeza) en la raza que tienen los diferentes grupos humanos, pues no existe fundamento científico para definir el concepto de raza. Por ejemplo, en mi propio trabajo de campo, con campesinos y mapuches en el interior neuquino, estos últimos habitualmente me decían que eran una raza. Automáticamente yo traducía el término raza a etnia; y sinceramente no creo que yo haya sido el único antropólogo que cometió ese error en los últimos años.

Me pregunto entonces si subordinar los conflictos étnicos y raciales a conflictos socioeconómicos no es una forma de ocultar que, al fin y al cabo, la mayoría de los antropólogos argentinos pertenecemos a la clase media urbana, somos descendientes de colonos e inmigrantes europeos y que nuestra etnia es la etnia (cultural y fenotípica) dominante que controla el Estado nación argentino, si bien no todos pertenecemos a la clase social que lo controla desde el punto de vista económico. Si no hemos hecho de Bórmida y algunos más, chivos expiatorios en dónde colocar todas las falencias (políticas, ideológicas y teóricas), para finalmente quedarnos con la conciencia tranquila de que nosotros somos mejores intelectuales y mejores personas que ellos.

Volviendo al eje del artículo, y para cerrar, mi interés no fue solamente denunciar a Bórmida por haber realizado estudios de tendencia racista. Claro que el racismo es algo que debemos denunciar, pero tampoco debemos ser tan inocentes pensando que con eliminar el término raza el racismo se acabó. Tampoco debemos permitir, creo, historias de la antropología que, descubriendo errores en viejos autores, nos sirvan para tapar nuestros propios y actuales problemas de análisis. Por ello, en primer lugar intenté ver aquello que Bórmida hacia en y durante sus investigaciones; y luego cuales eran sus postulados centrales para no caer en posiciones sociocéntricas concluyendo que Bórmida era un mal antropólogo porque no pensaba ni hacía lo que nosotros hoy haríamos al realizar una investigación. Así descubrimos que si realizamos una lectura sociológica de la primera obra de Bórmida ésta siempre nos va a parecer mal realizada por el simple hecho de que las categorías centrales de las que él partía no eran sociológicas sino raciológicas. Que esto tenía implicancias políticas es evidente. Pero no nos libra automáticamente de las implicancias políticas que podrían llegar a tener nuestras propias afirmaciones. Bórmida no es un otro radicalmente opuesto a un nosotros. Claro es que debemos denunciar su racismo. Pero creo también es importante analizar autores pasados y escuelas que ya están un poco obsoletas desde un punto de vista no autocentrado. Tratando de comprender cuales eran los valores, principios y categorías centrales que los autores y escuelas tenían. Sólo esto nos permitirá establecer comparaciones válidas entre esas antropologías y las que se realizan en la actualidad de una forma simétrica, o sea, una antropología que justamente no establezca jerarquías apriorísticas en dónde casualmente nuestra posición (científica y política) siempre es mejor (y superior) respecto a la (también supuestamente) posición opuesta.

Buenos Aires, 25 de febrero del 2012

\section{Agradecimientos}

Este trabajo se realizó en el marco del PICT-SECyT "Antropología social e histórica del campo antropológico en Argentina (1940-1980)". Nodo Olavarría/FACSOUNICEN. Quisiera agradecer los comentarios del equipo en cuestión, Rosana Guber, Mirta Bonin, Andrés Laguens, Gastón Gil, Germán Soprano, Belén Hirose, Susana Luco, Mariela Zabala, Sergio Carrizo y Paula Macario. También a Laura Zapata por guiarme en algunos problemas referentes al tema de la raza y el racismo. Por último, a 
los dos evaluadores anónimos de ésta revista.

\section{Bibliografía}

Arenas, P, E. I. Baffi 1991-1992 José Imbelloni: una lectura crítica. Runa. Archivos para la ciencia del Hombre XX: 167-176.

Arenas, P. 2002-2003 Alfred Métraux y su visión del mundo indígena en los trabajos etnográficos en el Chaco argentino. Société suisse des Américanistes / Schweizerische Amerikanisten-Gesellschaft, Bulletin 6667: 127-132

Banton, M. 1977 A idéia de raça. Lisboa: Edições 70

Billinger, M. S. 2007 Another Look at Ethnicity as a Biological Concept: Moving anthropology Beyond the Race Concept. Critique of Anthropology 27 (1) 5-35

Briones, C., R. Guber 2008 Argentina: Contagious Marginalities. En Poole, Deborah (ed.) A Companion to Latin American Anthropology. Oxford, Blackwell. 11-31.

Bórmida, M. 1949 El acrómetro. Instrumento para medir la altura cefálica. Runa. Archivos para la ciencia del Hombre II (1-2): 126-138.

Bórmida, M. 1949 Sepultura colectiva bajo roca en la Patagonia austral. Runa. Archivos para la ciencia del Hombre II (1-2): 148-155

Bórmida, M. 1950 Curioso objeto lítico de la Península de Valdés. Runa. Archivos para la ciencia del Hombre III (1-2): 231-235.

Bórmida, M. 1951 Algunas luces sobre la penumbrosa historia de Pascua. Runa. Archivos para la ciencia del Hombre IV (1-2): 5-62

Bórmida, M. 1951 Formas y funciones del matá, el más conocido artefacto de la arqueología de Pascua. Runa. Archivos para la ciencia del Hombre IV: 296-308.

Bórmida, M. 1951 "Somatología de la Isla de Pascua" En: Runa. Archivos para la ciencia del Hombre. IV (1-2): $178-222$

Bórmida, M. 1953 Los antiguos patagones. Tesis doctoral, FFyL-UBA

Bórmida, M. 1953-1954 Los antiguos patagones. Estudio de craneología. Runa. Archivos para la ciencia del
Hombre VI (1-2): 5-96

Bórmida, M. 1955 Recientes estudios sobre los antiguos habitantes de la Patagonia. Separata CIA, 31. Sao Paulo. Anais Vol.2

Bórmida, M. 1958-1959 Bosquejo para una Historia general del pensamiento etnológico. II Parte. La antropología del materialismo. Runa. Archivos para la ciencia del Hombre IX (1-2): 51-98

Carnese, F., J. Cocilovo y A. Goicoechea 1991-1992 Análisis histórico y estado actual de la Antropología Biológica en la Argentina. Runa. Archivos para la ciencia del Hombre XX: 35-67.

Fígoli, L. H. G. 1990 A ciência sob o olhar etnográfico. Estudo da antropologia argentina. Tesis de doctorado (inédita). Brasilia. Universidade Nacional de Brasilia

Garbulski, E. O. 1991-1992 La antropología social en la Argentina. Runa. Archivos para la ciencia del Hombre XX: 11-33.

Graebner, F. 1940 [1911] Metodología etnológica. Universidad Nacional de La Plata

Imbelloni, J. 1916 La bio-filosofía de la guerra y William Mackenzie. Revista de Filosofía. S/N Buenos Aires

Kaszycka, K. A., G. Štrkalj y J. Strzałko. 2009. Current Views of European anthropologist on Race: Influence of Educational and Ideological Background. American Anthropologist. 111 (1): 43-56

Menghín, O. F.A 1953-1954 El desarrollo de las culturas, a propósito de una obra recentísima. Runa. Archivos para la ciencia del Hombre VI (1-2): 200-210

Needham, R. 2006 Prefacio a la edición en español, en Los semisabios, A. Van Gennep. Buenos Aires. EUDEBA.

Rivet, P. 1974 [1957] Los orígenes del hombre americano. México. Fondo de Cultura Económica.

González, A. R. 1991-9292 A cuatro décadas del comienzo de una etapa. Apuntes marginales para la historia de la antropología argentina. Runa. Archivos para la ciencia del Hombre XX: 91-110.

Silla, R. 2010 Pureza de origen: la expedición argentina a Rapa Nui. Estudios en Antropología Social 1 (2): 17-35. 